\title{
Terminologia em seriados médicos: os procedimentos de tradução na legendagem
}

\section{Terminology in Medical Drama TV Shows: Translation Procedures of the Subtitles}

\author{
Thaís Collet \\ Ina Emmel ${ }^{*}$
}

Resumo: Este trabalho analisa os procedimentos de tradução da terminologia médica apresentada nas legendas em português do seriado ER, com base na Teoria Comunicativa de Cabré (1999), e os compara com os resultados de uma análise anterior do seriado House (COLLET 2012) com o objetivo de verificar qual o procedimento predominante. A análise, que se deteve a apenas um episódio do seriado ER e aos termos referentes a aparelhos e exames, revelou o predomínio de procedimentos de equivalência, assim como havia demonstrado a análise anterior de quatro episódios do seriado House (COLLET 2012), confirmando, portanto, a importância dos termos para representar o conhecimento especializado.

Palavras-chave: procedimentos de tradução; terminologia médica; legendagem; seriados ER e House.

Abstract: This paper presents the analysis of translation procedures in the Portuguese subtitles of medical terms from one episode of the TV sitcom ER, based on Cabré's Communicative Theory of Terminology (1999) and compares it with a previous analysis of the medical terminology of the TV show House (COLLET 2012). The goal was to verify which the main translation procedure was used. Only the terminology of one episode

\footnotetext{
" Doutoranda no Programa de Pós-graduação em Estudos da Tradução da Universidade Federal de Santa Catarina. Email: thacollet@gmail.com

** Professora do Departamento de Língua e Literatura Estrangeiras e do Programa de Pósgraduação em Estudos da Tradução da Universidade Federal de Santa Catarina. Email: inaemmel@gmail.com
} 
Collet, T.; Emmel, I. - Terminologia em seriados médicos: os procedimentos de tradução na legendagem

was analyzed and only terms related to machines and exams. Translations by equivalents prevailed in ER as showed the previous analysis of four episodes of House (COLLET 2012), which confirmed the terms importance in specialized communication.

Keywords: translation procedures; medical terminology; subtitling; ER and House.

\section{Introdução}

Este artigo parte do resultado da dissertação de Collet (2012), que analisou a tradução da terminologia médica no seriado House e faz agora uma comparação com o mesmo percurso analítico aplicado à terminologia extraída de outro seriado médico, o seriado ER. $O$ objetivo é, ao verificar os procedimentos usados para traduzir para as legendas os termos referentes a exames e aparelhos, averiguar se, assim como na análise do seriado House, o uso do procedimento de equivalência é o que predomina.

$\mathrm{Na}$ área da Terminologia, este trabalho se embasa na Teoria Comunicativa da Terminologia (CABRÉ 1999) ${ }^{1}$ e, para os procedimentos de tradução dos termos nas legendas, nas discussões adotadas em Collet (2012).

Ainda que se analisem aqui os procedimentos de tradução, ressalta-se que há ciência das tecnicalidades da legendagem, especialmente as limitações temporais e espaciais deste tipo de tradução ${ }^{2}$. 0 tempo que cada legenda permanece na tela é determinante para o número máximo de caracteres que o tradutor poderá usar, pois é necessário que haja tempo para leitura (MARTINEZ [2007] afirma que o padrão usado no Brasil é de 15 caracteres por segundo). Neste artigo, não será trabalhado o tempo de duração das legendas dos

\footnotetext{
${ }^{1}$ A escolha pela Teoria Comunicativa de Cabré (1999) foi por sua visão não normalizadora e estática e por acreditar que cubra a atual necessidade de abrangência e diversidade dos termos, assim como também consideram Krieger, Maciel e Finatto (2000) e Krieger e Finatto (2004).

2 Para mais detalhes sobre o processo de legendagem ver MARTINEZ (2007) e Carvalho (2005).
} 
Collet, T.; Emmel, I. - Terminologia em seriados médicos: os procedimentos de tradução na legendagem

seriados, assim, somente citam-se os procedimentos de tradução sem cogitar hipóteses sobre o porquê das escolhas.

$\mathrm{Na}$ pesquisa de mestrado de Collet (2012), foram analisados os primeiros quatro episódios da segunda temporada do seriado House - Aceitação (Acceptance), Autópsia (Autopsy), A queda do telhado (Humpty Dumpty) e Tuberculose (TB or not TB). Neste artigo, é analisado um episódio de ER Plantão Médico (23 episódio da primeira temporada - Motherwood), seriado que, assim como House, tem como plano de fundo um hospital e no qual a terminologia é usada para representar o contexto profissional e transmitir o conhecimento especializado, o que, segundo Cabré (1999), é o papel primordial dos termos dentro desse tipo de discurso. A terminologia, segundo ela (1999: 187, tradução nossa ${ }^{3}$ ), é a base da comunicação entre os especialistas:

As linguagens de especialidade são os instrumentos básicos de comunicação entre os especialistas; e a terminologia, seu elemento mais importante para precisar cognitivamente seus sistemas de denominação. ${ }^{4}$

De acordo com Barros (2004: 44), um texto técnico, científico ou especializado é “o conjunto não finito dos discursos orais e escritos produzidos por uma área do saber ou do fazer humano [...]”. Ainda de acordo com a autora, “A principal característica desse tipo de texto encontra-se, [...], em nível lexical, uma vez que veicula unidades lexicais com conteúdos específicos do domínio em questão". Hurtado Albir (2011: 60) afirma que "ainda que os textos especializados apareçam mais na forma escrita, eles também podem ser orais e audiovisuais [...]". ${ }^{25}$ E os seriados discutidos neste trabalho se encaixam nessa

\footnotetext{
3 Todas as citações, quando em língua estrangeira, foram traduzidas no corpo do texto pelas autoras deste artigo e mantidos os originais em notas de rodapé.

4 "Los lenguajes de especialidad son los instrumentos básicos de comunicación entre los especialistas; y la terminol ogía, su el emento más importante para precisar cognitivamente sus sistemas de denominación."
} 
Collet, T.; Emmel, I. - Terminologia em seriados médicos: os procedimentos de tradução na legendagem

classificação, eles partem de uma fonte escrita, mas são representados na forma oral através de um programa audiovisual.

Cabré (1999: 197) discorre sobre a importância da tradução dos termos:

As unidades terminológicas são unidades repletas de conhecimento que conferem ao texto especializado seu carácter eficiente. A adequação e a naturalidade de uma tradução dependem, em grande parte, do uso preciso das unidades terminológicas reais. A transgressão deste princípio contribui para aumentar o ruído comunicativo em uma especialidade. ${ }^{5}$

Nota-se, portanto, a importância dos termos (permeando o discurso desses dois programas televisivos e que servem intencionalmente para conferir credibilidade de que se trata mesmo de uma fala entre especialistas) e, consequentemente, a importância da tradução dos mesmos também no contexto do entretenimento.

\section{O seriado House}

O seriado médico americano House iniciou em 2004 e terminou em 2012, na oitava temporada. No Brasil, é transmitido pela Universal Channel e pela Record. Os episódios analisados foram extraídos do DVD distribuído pela Universal e, apesar de não haver menção à tradução, Sabrina Martinez, então sócia da Gemini Media e que também já traduziu episódios do seriado House (MARTINEZ 2010), confirmou por e-mail que a tradução para legendagem foi

\footnotetext{
5 "Las unidades terminológicas son unidades comprimidas de conocimiento que confieren al texto especializado su carácter eficiente. La adecuación y naturalidad de una traducción depende en gran medida del recto uso de las unidades terminológicas reales. La transgresión de este principio contribuye a aumentar el ruido comunicativo en una especialidad."
} 
Collet, T.; Emmel, I. - Terminologia em seriados médicos: os procedimentos de tradução na legendagem

realizada pela empresa, que ficou responsável também pelas legendas do seriado transmitido na TV, no canal Universal Channel6.

Collet (2012) argumenta que o seriado House apresenta os elementos que caracterizam a linguagem de especialidade, amparados na Teoria de Cabré (1999: 187-188): a) especificidade do tema e sua perspectiva cognitiva; b) os interlocutores, com seus usuários sendo especialistas de uma matéria específica; c) a terminologia, pois, como o conhecimento especializado se materializa nos termos, quanto mais especializado o texto, maior a densidade terminológica. Para Collet (2012: 20) estes três itens são confirmados no seriado de ficção:

[...] o tema faz parte de uma área específica, a medicina; seus interlocutores, os personagens, embora ficcionais, representam os especialistas ao interpretar os roteiros que são redigidos e revisados por especialistas; e seus diálogos estão repletos de termos da área médica.

O seriado House tem entre os seus roteiristas, David Foster, médico formado pela Harvard Medical School (NADALE 2009) e conta, de acordo com Shore (2006), com três médicos, que atuam como consultores e conferem os roteiros, e ainda com uma enfermeira que participa em tempo integral das gravações nos sets de filmagem. Ao final dos episódios do DVD, é possível ler nos créditos os nomes desses consultores ${ }^{7}$.

Nos quatro episódios do seriado House analisados em Collet (2012), foram encontrados 29 termos referentes a aparelhos e exames com 88 ocorrências. Os termos foram apresentados com suas definições em inglês e português,

\footnotetext{
${ }^{6} \mathrm{Na}$ TV, ao final dos episódios aparece o nome do tradutor, o que é importante para o reconhecimento do trabalho do profissional.

${ }^{7}$ Apesar de toda a preocupação dos produtores quanto ao "realismo" do seriado, ele é ficcional e passível de falhas. No livro A ciência médica de House, o qual discorre sobre a veracidade do programa, Holtz (2008) cita, como exemplo, o fato de a mesma equipe de médicos coordenada por House realizar desde exames laboratoriais a cirurgias médicas, e a rapidez na qual são dados os resultados dos exames, o que dificilmente acontece numa situação hospitalar real.
} 
Collet, T.; Emmel, I. - Terminologia em seriados médicos: os procedimentos de tradução na legendagem

transcrição do áudio em inglês e legendas em português, acompanhados do procedimento tradutório. Collet (2012: 45-56) apresenta 12 procedimentos ${ }^{8}$ :

a. equivalente ${ }^{9}$ : uso equivalente, assim como usa Cabré (1999) para os termos que nas duas línguas possuam o mesmo conceito, o que pode ser percebido pelas definições encontradas. [...]

b. paráfrase: uso paráfrase, bem como usa Cabré (1999), para a tradução que explica o termo com outras palavras (o mesmo que a técnica de "descrição" de Molina e Hurtado Albir (2002)).[...]

c. generalização: como citam MoLINA e Hurtado Albir (2002), a generalização ocorre quando um termo foi traduzido por um hiperônimo, uma palavra mais geral. [...]

d. particularização: também citado por Molina e Hurtado Albir (2002), o contrário de generalização, quando é usado um termo mais específico. [...]

e. equivalente reduzido: uso para os termos traduzidos que não correspondiam à forma integral do nome em português. [...]

f. transposição: quando um termo em uma classe gramatical é usado em outra. A transposição é citada por Molina e Hurtado Albir (2002) referindo-se ao procedimento já explicado por Vinay e Darlbenet (2000).

g. equivalente inadequado ${ }^{10}$ : utilizo-o, bem como fizeram Lozano e Matamala (2009). A "equivalência de tradução inadequada" é citada por Hurtado Albir (2011: 308) quando define o que seria um “erro de tradução". A discussão sobre “erros” é longa, por isso me limito neste trabalho a usar "equivalente inadequado" nas traduções que apresentaram um termo com significado distinto do termo apresentado no original, sem especificar outros tipos de erros e sem entrar na questão de processo e/ou competência. ${ }^{11}[\ldots]$

h. omissão ${ }^{12}$ : quando os termos médicos, falados no original, em inglês, foram completamente omitidos na tradução. [...]

\footnotetext{
8 Para exemplos e mais discussão a respeito dos procedimentos, ver Collet (2012: 49-56)

9 Collet (2012: 49) usa "[...] "equivalente" por ser este usado por Cabré (1999) dentro da TCT. BAJAJ (2009) chama a atenção para o fato de que apesar de ser um termo polêmico dentro dos ET, alguns autores afirmam que dentro da medicina a completa equivalência dos termos não é incomum (ARNTZ et al 2004, STOLZE 2001 apud BAJAJ 2009: 185). Para mais informações a respeito da noção de equivalência e toda polêmica em torno dela dentro dos ET, ver Bajaj (2009: 185), Shuttleworth e Cowie (1997: 49) e Kenny (1998: 77)."

100 termo "inadequado" não é usado como negação a "adequado", pois o termo "adequação" já é usado nos ET, com diferentes significados, como explicam Shuttleworth e Cowie (1997) no Dictionary of Translation Studies (Collet 2012: 53).

${ }^{11}$ Para saber mais sobre erros de tradução, ver Hurtado Albir (2011: 289-308).

${ }^{12}$ Collet (2012: 61) explica que:
} 
Collet, T.; EMmeL, I. - Terminologia em seriados médicos: os procedimentos de tradução na legendagem

i. omissão com acréscimo de informação: quando o termo foi omitido, mas foi acrescida alguma informação a respeito, sendo que esta informação não poderia ser considerada uma paráfrase por não explicar o termo em questão [...]

j. alteração: usarei "alteração" para a tradução na qual, suponho, o tradutor tenha mudado o texto por considerar o original inapropriado. [...]

k. troca de termo sem alteração de sentido: quando o tradutor usou outro termo, porém isso não afetou o sentido final do enunciado, não considerando, assim, inadequado. [...]

l. tradução literal: tradução do termo palavra por palavra. [...]

No Gráfico 1, apresenta-se o resultado dos procedimentos de tradução encontrados na análise dos quatro episódios do seriado House por Collet (2012). ${ }^{13}$

Revendo as técnicas de tradução propostas por Molina e Hurtado Albir (2002), não conseguiria encaixar a "omissão", percebida neste exemplo, em nenhuma delas. A mais próxima, a meu ver, seria a "redução". No entanto, como Molina e Hurtado Albir (2002) explicam a técnica de redução, entendo que a supressão seria somente da explicação do termo em questão para públicos aos quais a explicação seria desnecessária, como no exemplo citado pelas autoras, no qual se retira a explicação "mês muçulmano de jejum" na tradução de "Ramadã" para o árabe. Apesar de as autoras incluírem a "omissão", classificada por Vázquez-Ayora (1977), dentro da "redução", vejo diferenças entre elas. Vázquez-Ayora (1977) cita como os casos mais comuns de omissão na tradução do inglês para o espanhol: simples repetição, auxiliar "can", particípio presente do verbo "to use", algumas preposições, artigos e outros determinantes, sujeito pronominal e o "it", alguns advérbios, só para citar alguns exemplos. Portanto, ele se refere particularmente a elementos sintáticos e não lexicais no sentido estrito, que é o que vem a ser especialmente o caso neste trabalho. Baker (1992: 40) também cita a "omissão", esta como uma estratégia de tradução usada para solucionar problemas, no nível de palavras, quando não há um equivalente. A autora comenta que palavras que em determinados contextos não sejam vitais podem ser omitidas. Apesar disso, ela complementa que "there is inevitably some loss of meaning when words and expressions are omitted in a translation" (BAKER 1992: 41).

${ }^{13}$ Para explicação de cada procedimento pormenorizadamente e dentro de parâmetros teóricos específicos, ver Collet (2012: 75-104). 
Collet, T.; Emmel, I. - Terminologia em seriados médicos: os procedimentos de tradução na legendagem

Gráfico 1 - Procedimentos no seriado House

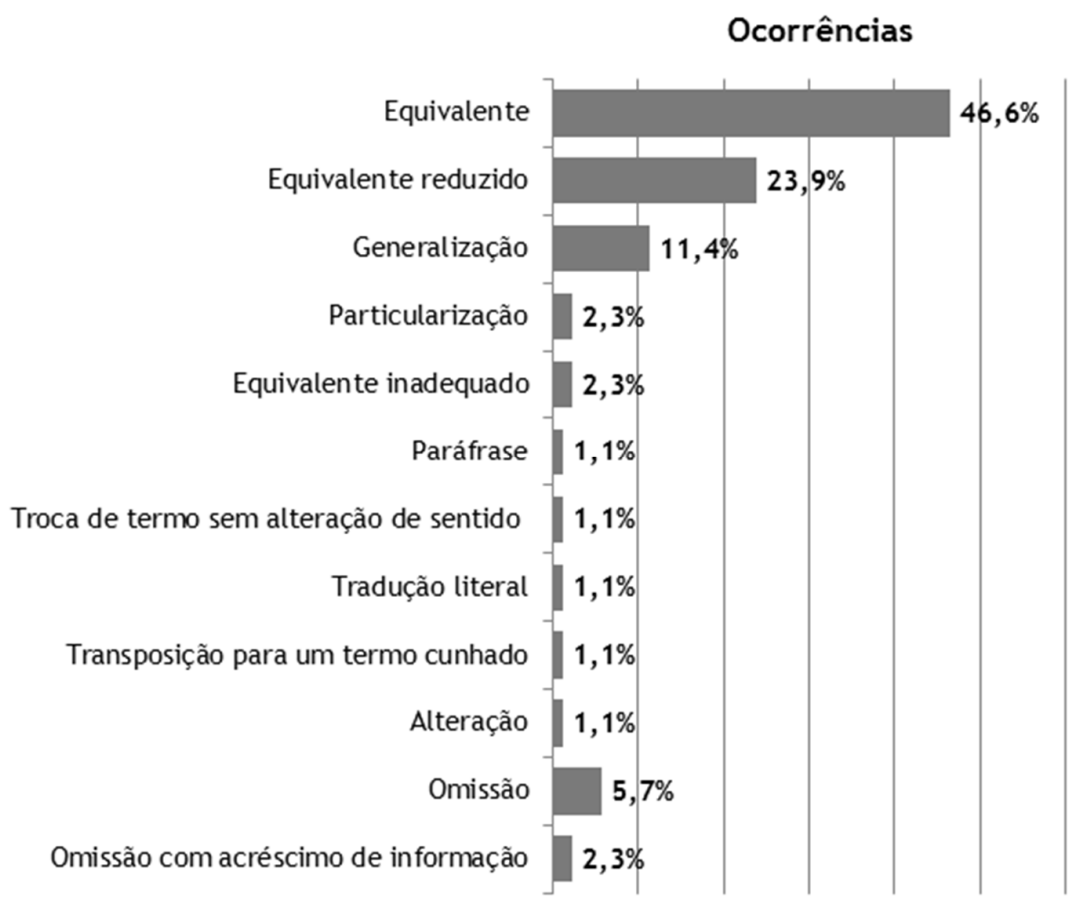

Fonte: Collet (2012: 108)

Como observa-se no Gráfico 1 apresentado acima, houve um predomínio de equivalentes e equivalentes reduzidos, representando 70,05\% das ocorrências. Uma análise semelhante a essa foi feita em um episódio do seriado ER e será apresentada a seguir.

\section{O seriado ER}

O seriado ER foi exibido pela primeira vez em 1994 e ficou no ar durante quinze temporadas até 2009. Ganhou vários prêmios e, segundo Nadale (2009), “[...] se tornou o drama mais assistido na TV americana exatamente por causa da atenção aos detalhes". Nos extras do último DVD da primeira temporada, é possível assistir a um interessante documentário sobre a realidade médica no seriado e as dificuldades para fazê-lo parecer verossímil. 0 documentário mostra um médico assistindo aos atores nos sets de filmagem. 0 criador do 
Collet, T.; Emmel, I. - Terminologia em seriados médicos: os procedimentos de tradução na legendagem

programa foi Michael Crichton, formado pela Harvard Medical School. Ainda que o episódio analisado não tenha sido escrito por um especialista da área, há, nos créditos finais, o nome de um médico consultor e de um consultor técnico. Isso mostra que, assim como no seriado House, apesar de ser um seriado ficcional, há preocupação com a verossimilhança, e os termos corroboram para representar e transmitir o conhecimento especializado, que, segundo Cabré (1999), é a função dos termos.

No DVD da primeira temporada, que só foi lançado no Brasil em 2004, não há informações a respeito da autoria das traduções.

\section{Análise dos termos em ER}

Abaixo, discutem-se os 10 termos referentes a exames e aparelhos que apareceram no episódio, 05 termos apareceram mais de uma vez, ocasionando, portanto, 17 ocorrências. Assim como em Collet (2012), para cada termo são apresentadas as definições em inglês e português para confirmar os termos empregados ${ }^{14}$. As definições, neste trabalho, foram de extrema importância, pois, como afirma Emmel (1998: 22), "a definição serve [...] para formular sintaticamente as características relevantes de um termo". Também Finatto (2003: 198) observa a importância das definições: "O enunciado definitório, como parece óbvio, é um elemento-chave na constituição e na veiculação do conhecimento especializado, tecnológico ou científico." Sendo cada termo, segundo a teoria adotada aqui, passível de definição, é exatamente através dela que se tem a certeza que se está mesmo diante de uma unidade terminológica. Para tanto, procurou-se por definições em dicionários e sites

\footnotetext{
${ }^{14}$ Assim como na análise do seriado House, alguns termos pré-selecionados foram excluídos da análise, após conferência das definições, por não tratarem do aparelho ou exame propriamente dito. Foi o caso de "paddles", que é uma parte do aparelho desfribilador (Machines called automated external defibrillators (AEDs) can be found in many public places, and are available for home use. These machines have pads or paddles to place on the chest during a lifethreatening emergency. (MEDLINE)); e de "spinal tap" e "LP", que são procedimentos para a retirada de material que serão usados posteriormente em testes laboratoriais.
} 
Collet, T.; Emmel, I. - Terminologia em seriados médicos: os procedimentos de tradução na legendagem

especializados nas duas línguas em análise que, uma vez encontradas, deram o aval de que realmente a unidade lexical extraída do discurso especializado subjacente ao seriado se constituía num termo e, então, partiu-se para a análise e enquadramento da solução tradutória oferecida para o mesmo nas legendas.

Nos quadros para discussão dos termos, na primeira coluna, há o tempo aproximado no qual o áudio apareceu na cena, sem apresentar a duração da legenda; na segunda, as transcrições do áudio em inglês; na terceira, as legendas em português (uma barra (/) foi usada para indicar a separação das linhas nas legendas com duas linhas); e na última, o procedimento de tradução. Nos quadros os termos analisados encontram-se destacados em negrito. Os termos aparecem listados em ordem alfabética.

\section{O termo "blood gas"}

Blood gas [sinônimos: arterial blood gas analysis e ABG]: Blood gases is a measurement of how much oxygen and carbon dioxide is in your blood. It also determines the acidity $(\mathrm{pH})$ of your blood. [...] The blood gases test is performed by collecting a sample of blood through a needle from an artery. The test is used to evaluate respiratory diseases and conditions that affect the lungs, and it is used to determine the effectiveness of oxygen therapy. The acid-base component of the test also gives information on how well the kidneys are functioning (MEDLINE).

Gasometria arterial: É um exame de sangue, que pode ser colhido em artéria (gasometria arterial) ou veia, (central (próxima do coração) ou periférica (nos membros) (gasometria venosa)). Tem por objetivo revelar valores da pressão parcial de gás carbônico e oxigênio, revelar o pH do sangue (que indicará a acidez ou alcalinidade do mesmo) e o valor do Bicarbonato, uma importante substância do sistema de regulação da acidez e alcalinidade do nosso corpo. Informa também o valor da Saturação da Oxi-hemoglobina: ou seja, quanto a hemoglobina, que é uma molécula que carrega o oxigênio pelo sangue até as células, está ligada a ele ou não. É exame básico e fundamental para uma unidade de terapia intensiva (LEITE 2007). 
Collet, T.; Emmel, I. - Terminologia em seriados médicos: os procedimentos de tradução na legendagem

Quadro 3 - Termo "Blood gas" em ER

\begin{tabular}{|c|c|c|c|}
\hline Tempo & $\begin{array}{c}\text { Transcrição do áudio } \\
\text { em inglês }\end{array}$ & $\begin{array}{c}\text { Legenda em } \\
\text { português }\end{array}$ & Procedimentos \\
\hline 9m12s & I'll draw a blood gas. & Gasometria. & Equivalente reduzido. \\
\hline 23m06s & $\begin{array}{c}\text { Oh, right, let's } \\
\text { hyperventilate him } \\
\text { Let a blood gas. }\end{array}$ & $\begin{array}{c}\text { Vamove hiperventilar } \\
\text { já! /E quero uma } \\
\text { gasometria. }\end{array}$ & Equivalente reduzido \\
\hline $39 \mathrm{~m} 51 \mathrm{~s}$ & $\begin{array}{c}\text { Draw up five of } \\
\text { morphine, start on a } \\
\text { nitroglycerin drip } \\
\text { and get a blood gas. }\end{array}$ & $\begin{array}{c}\text { Aplique } 5 \text { de morfina, } \\
\text { ponha/ nitroglicerina } \\
\text { no soro. E } \\
\text { gasometria. }\end{array}$ & Equivalente reduzido. \\
\hline
\end{tabular}

Fonte: Elaborado pelas autoras.

O equivalente em português para “blood gas" seria "gasometria arterial”. Devido à tradução não especificar a via (artéria ou veia), o procedimento foi considerado como "equivalente reduzido". Não se considera como "generalização", por entender que neste caso seria usado apenas “exame".

\section{O termo "blood work"}

Blood test [sinônimo: blood work]: Any diagnostic testing performed on the fluid or cells of peripheral blood (TERMIUM).

Teste de sangue: teste para determinar as características químicas, físicas ou sorológicas do sangue, ou de alguma parte constituinte do sangue (THOMAS 2000).

Quadro 4 - 0 termo "blood work" em ER

\begin{tabular}{|c|c|c|c|}
\hline Tempo & $\begin{array}{c}\text { Transcrição do áudio } \\
\text { em inglês }\end{array}$ & Legenda em português & Procedimentos \\
\hline
\end{tabular}


Collet, T.; EmMEL, I. - Terminologia em seriados médicos: os procedimentos de tradução na legendagem

\begin{tabular}{|c|c|c|c|}
\hline 20m29s & $\begin{array}{c}\text { We need to do more } \\
\text { blood work and get a } \\
\text { chest x-ray. }\end{array}$ & $\begin{array}{c}\text { Faremos outros } \\
\text { exames de sangue / e } \\
\text { um raio } x \text { do peito. }\end{array}$ & Equivalente \\
\hline
\end{tabular}

Fonte: Elaborado pelas autoras.

Considerando "teste de sangue", como sinônimo de "exame de sangue", o termo "blood work" foi traduzido por seu equivalente em português.

\section{O termo "CBC"}

The complete blood count (CBC) is a test that measures the levels of different cells, like red blood cells, white blood cells, and platelets, in the blood (AMERICAN CANCER SOCIETY).

Hemograma: Nome que Schilling deu ao conjunto da contagem e morfologia das células do sangue que permite conclusões diagnósticas e prognósticas, uma vez observados os dados clínicos. Contagem de células do sangue (LEITE 2007).

Quadro 5 - Termo "CBC" em ER

\begin{tabular}{|c|c|c|c|}
\hline Tempo & $\begin{array}{c}\text { Transcrição do áudio } \\
\text { em inglês }\end{array}$ & Legenda em português & Procedimentos \\
\hline $8 \mathrm{~m} 16 \mathrm{~s}$ & $\begin{array}{c}\text { CBC, type and cross } \\
\text { eight units? }\end{array}$ & $\begin{array}{c}\text { Não houve legenda } \\
\text { para esta fala. }\end{array}$ & Omissão \\
\hline $10 \mathrm{~m} 49 \mathrm{~s}$ & $\begin{array}{c}\text { Get a CBC, Chem-7 and } \\
\text { prep for an LP. }\end{array}$ & $\begin{array}{c}\text { Quero um hemograma, } \\
\text { análise química e } \\
\text { prepare-a para uma } \\
\text { punção lombar. }\end{array}$ & Equivalente \\
\hline $31 \mathrm{~m} 36 \mathrm{~s}$ & $\begin{array}{c}\text { Let's get a CBC, chem- } \\
\text { 7, type and cross two } \\
\text { units. }\end{array}$ & $\begin{array}{c}\text { Façam um } \\
\text { hemograma, análise } \\
\text { química/ e exame de } \\
\text { sangue. }\end{array}$ & \begin{tabular}{c} 
Equivalente \\
\hline
\end{tabular} \\
\hline
\end{tabular}

Fonte: Elaborado pelas autoras. 
Collet, T.; EMmeL, I. - Terminologia em seriados médicos: os procedimentos de tradução na legendagem

“CBC" foi traduzido duas vezes pelo seu equivalente em português, “hemograma"15. Em 8m16s, escuta-se uma fala, porém não houve legenda, ocorrendo, portanto, uma “omissão". Como não foi extraído o tempo de entrada e saída das legendas não é possível afirmar se esta omissão ocorreu por imposição das tecnicalidades da legendagem como falta de tempo ou de espaço. Também não há como afirmar se realmente implicou no entendimento da cena, pois não foi feita uma pesquisa com espectadores, porém, observa-se que não havia imagens que ilustrassem visualmente os exames a serem feitos e, assim, o espectador brasileiro, sem a tradução, ficou sem essa informação.

\section{O termo "chem- 7"}

Basic metabolic panel (sinônimos: Chem - 7): the basic metabolic panel is a group of blood tests that provides information about your body's metabolism (MEDLINE).

O exame CHEM-7, às vezes chamado de Perfil ou Painel Metabólico Básico (BMP), é uma bateria de exames químicos do sangue $(\text { WIKIPEDIA })^{16}$

Quadro 6 - O termo "chem-7" em ER

\begin{tabular}{|c|c|c|c|}
\hline Tempo & $\begin{array}{c}\text { Transcrição do áudio } \\
\text { em inglês }\end{array}$ & Legenda em português & Procedimentos \\
\hline $10 \mathrm{~m} 49 \mathrm{~s}$ & $\begin{array}{c}\text { Get a CBC, Chem-7 } \\
\text { and prep for an LP. }\end{array}$ & $\begin{array}{c}\text { Quero um hemograma, } \\
\text { análise química e } \\
\text { prepare-a para uma } \\
\text { punção lombar. }\end{array}$ & Generalização \\
\hline
\end{tabular}

${ }^{15} \mathrm{O}$ site Lab Tests Online, produzido pela American Association for Clinical Chemistry indica "hemogram" como sinônimo de "CBC".

16 Disponível em: http://pt.wikipedia.org/wiki/Exame_de_sangue. Acesso em: 02 mai 2013. Não foi encontrada uma definição para o termo em dicionários especializados, por isso, foi utilizada a Wikipédia, ainda que se reconheça que não é a melhor opção. 
Collet, T.; Emmel, I. - Terminologia em seriados médicos: os procedimentos de tradução na legendagem

\begin{tabular}{|c|c|c|c|}
\hline 31m36s & $\begin{array}{c}\text { Let's get a CBC, Chem- } \\
\text { 7, type and cross two } \\
\text { units. }\end{array}$ & $\begin{array}{c}\text { Façam um hemograma, } \\
\text { análise química/ e } \\
\text { exame de sangue. }\end{array}$ & Generalização \\
\hline
\end{tabular}

Fonte: Elaborado pelas autoras.

Considerou-se que o procedimento tenha sido uma generalização por não especificar o nome do exame.

\section{O termo "chest film"}

Chest film: Most common X-ray used to detect abnormalities in or within the thoracic cage, such as the lungs, heart, aorta, and the bones of the chest. Extra metallic objects, such as jewelry are removed from the chest and neck areas for a chest $\mathrm{x}$-ray to avoid interference with $x$-ray penetration and improve accuracy of the interpretation (MEDICINENET).

Quadro 7 - Termo "chest film" em ER

\begin{tabular}{|c|c|c|c|}
\hline Tempo & $\begin{array}{c}\text { Transcrição do áudio } \\
\text { em inglês }\end{array}$ & Legenda em português & Procedimentos \\
\hline $8 \mathrm{~m} 10 \mathrm{~s}$ & $\begin{array}{c}\text {-Malik, call radiology. } \\
\text { Let's get a portable } \\
\text { chest film. } \\
\text {-You got it. }\end{array}$ & $\begin{array}{c}\text {-Malik, vamos fazer um } \\
\text { raio x. } \\
\text {-Pra já! }\end{array}$ & Equivalente reduzido \\
\hline $31 \mathrm{~m} 39 \mathrm{~s}$ & $\begin{array}{c}\text { Get a chest film and } \\
\text { do a CT on the way to } \\
\text { ICU. }\end{array}$ & $\begin{array}{c}\text { Façam uma } \\
\text { radiografia/ a caminho } \\
\text { para a UTI }\end{array}$ & Equivalente reduzido \\
\hline
\end{tabular}

Fonte: Elaborado pelas autoras.

Nas duas ocorrências não foi traduzida a parte do corpo na qual seria feita a radiografia ${ }^{17}$, ou seja, o peito, portanto, considera-se que houve uma

${ }^{17}$ Ver definições no termo "chest x-ray". 
Collet, T.; Emmel, I. - Terminologia em seriados médicos: os procedimentos de tradução na legendagem

tradução usando um “equivalente reduzido". Na primeira também não há menção a "portable".

\section{O termo "chest $\mathrm{x}$-ray"}

X-ray: An image obtained by means of X-rays (MEDTERMS).

Radiography: The making of film records (radiographs) of internal structures of the body by passage of $x$-rays or gamma rays through the body to act on specially sensitized film (TERMIUM).

Raios X: Radiação eletromagnética produzida pela excitação dos elétrons da órbita interna de um átomo (LEITE 2007)

Radiografia: É um exame clínico baseado na produção de Raios X. (LEITE 2007).

Quadro 8 - 0 termo "chest x-ray" em ER

\begin{tabular}{|c|c|c|c|}
\hline Tempo & $\begin{array}{c}\text { Transcrição do áudio } \\
\text { em inglês }\end{array}$ & Legenda em português & Procedimentos \\
\hline $20 \mathrm{~m} 29 \mathrm{~s}$ & $\begin{array}{c}\text { We need to do more } \\
\text { blood work and get a } \\
\text { chest } \mathrm{x} \text {-ray. }\end{array}$ & $\begin{array}{c}\text { Faremos outros exames } \\
\text { de sangue/ e um raio } \mathrm{x} \\
\text { do peito. }\end{array}$ & Equivalente \\
\hline
\end{tabular}

Fonte: Elaborado pelas autoras.

"Chest x-ray" foi traduzido por "raio x do peito", portanto, um "equivalente".

\section{O termo “CT"}

A Computed Axial Tomography or CT scan is a test that provides very clear pictures of structures inside the body (Sinônimos: CAT scan; Computed axial tomography scan; Computed tomography scan) (MEDLINE). 
Collet, T.; Emmel, I. - Terminologia em seriados médicos: os procedimentos de tradução na legendagem

Apesar de não trazer uma definição para "CT scan", o banco de termos do governo canadense Termium o traz como sinônimo de "Computed tomogram", que, segundo o site, são imagens criadas pela técnica que o banco traz como "CT", "Computed tomography" e "CT scanning".

Tomografia computadorizada: Imagens de estruturas corpóreas criada por um computador, que retira as imagens do raio $\mathrm{x}$ e transforma-as em imagens computadorizadas. A tomografia computadorizada permite que o médico visualize certos tecidos e estruturas que não podem ser vistos pelo raio $X$ convencional (LEITE 2007).

Quadro 9 - 0 termo “CT” em ER

\begin{tabular}{|c|c|c|c|}
\hline Tempo & $\begin{array}{c}\text { Transcrição do áudio } \\
\text { em inglês }\end{array}$ & Legenda em português & Procedimentos \\
\hline $31 \mathrm{~m} 39 \mathrm{~s}$ & $\begin{array}{c}\text { Get a chest film and } \\
\text { do a } \mathbf{C T} \text { on the way to } \\
\text { ICU. }\end{array}$ & $\begin{array}{c}\text { Façam uma } \\
\text { radiografia/ a caminho } \\
\text { para a UTI }\end{array}$ & Omissão \\
\hline
\end{tabular}

Fonte: Elaborado pelas autoras.

A tomografia computadorizada, ainda que parta dos raios $\mathrm{x}$, permite mais detalhes que o exame convencional. Como no áudio em inglês foi pedido para serem feitos dois exames ("chest film" e "CT") e na tradução há somente "radiografia" no singular, foi entendido que houve omissão do termo "CT". Apesar da falta de informação completa, como já afirmado anteriormente, não é possível dizer se esta omissão ocorreu devido às tecnicalidades da legendagem, tampouco se comprometeu o entendimento do espectador.

\section{O termo “monitor"}

Monitor: An apparatus used to observe or record such physiological signs as respiration, pulse, and blood pressure in an anesthetized patient or one undergoing surgical or other procedures (TERMIUM). 
Collet, T.; EMmeL, I. - Terminologia em seriados médicos: os procedimentos de tradução na legendagem

Monitor: Rubrica: medicina. Aparelho automático que realiza a monitorização (HoUAISS 2007) ${ }^{18}$

Quadro 10 - 0 termo "monitor" em ER

\begin{tabular}{|c|c|c|c|}
\hline Tempo & $\begin{array}{c}\text { Transcrição do áudio } \\
\text { em inglês }\end{array}$ & Legenda em português & Procedimentos \\
\hline $32 \mathrm{~m} 49 \mathrm{~s}$ & $\begin{array}{c}\text {-Grab the monitor. } \\
\text {-Hand me the saline. }\end{array}$ & $\begin{array}{c}\text {-Pegue o monitor. } \\
\text {-Passe o soro. }\end{array}$ & Equivalente \\
\hline
\end{tabular}

Fonte: Elaborado pelas autoras.

“Monitor" foi traduzido por "monitor", ou seja, conforme pode-se constatar pelas definições, o procedimento tradutório foi o da "equivalência".

\section{O termo "nebulizer"}

A device or machine for converting a liquid into a fine spray, especially for medical use (TERMIUM).

Nebulizador: aparelho utilizado para aspergir líquido em gotículas minúsculas (ASADIC).

Quadro 11 - 0 termo "nebulizer" em ER

\begin{tabular}{|c|c|c|c|}
\hline Tempo & $\begin{array}{c}\text { Transcrição do áudio } \\
\text { em inglês }\end{array}$ & Legenda em português & Procedimentos \\
\hline $08 \mathrm{m04s}$ & $\begin{array}{c}\text {-He's wheezing. } \\
\text {-Albuterol nebulizer? }\end{array}$ & $\begin{array}{c}\text {-Está ofegante. } \\
\text {-Albuterol? }\end{array}$ & Omissão \\
\hline
\end{tabular}

Fonte: Elaborado pelas autoras.

$\mathrm{Na}$ tradução, só houve referência ao medicamento "broncodilatador albuterol" (MEDLINE), omitindo o aparelho usado para a nebulização. Esta

${ }^{18}$ Ainda que não seja um dicionário especializado, traz neste verbete a rubrica "medicina", indicando a área de especialidade que é usado, portanto, se tratando de um termo. 
Collet, T.; Emmel, I. - Terminologia em seriados médicos: os procedimentos de tradução na legendagem

omissão do aparelho deve, no entanto, ser amenizada, pois o medicamento pode ser aplicado através de um inalador ou de um aparelho nebulizador (MEDLINEPLUS), assim, o termo estaria implícito e a omissão da tradução não implicaria no entendimento da cena.

\section{O termo "type and cross"}

Apesar de não ter sido encontrada uma definição para "type and cross", Dean (2005) afirma que dois testes de sangue, conhecidos como "type and cross match", são feitos antes de uma transfusão de sangue para verificar o tipo sanguíneo e a compatibilidade.

Quadro 12 - 0 termo "type and cross" em ER

\begin{tabular}{|c|c|c|c|}
\hline Tempo & $\begin{array}{c}\text { Transcrição do áudio } \\
\text { em inglês }\end{array}$ & Legenda em português & Procedimentos \\
\hline $8 \mathrm{~m} 16 \mathrm{~s}$ & $\begin{array}{c}\text { CBC, type and cross } \\
\text { eight units? }\end{array}$ & $\begin{array}{c}\text { Não houve legenda } \\
\text { para esta fala. }\end{array}$ & Omissão \\
\hline $31 \mathrm{~m} 36 \mathrm{~s}$ & $\begin{array}{c}\text { Let's get a CBC, chem- } \\
7, \text { type and cross two } \\
\text { units. }\end{array}$ & $\begin{array}{c}\text { Façam um hemograma, } \\
\text { análise química/ e } \\
\text { exame de sangue. }\end{array}$ & Generalização \\
\hline
\end{tabular}

Fonte: Elaborado pelas autoras.

$\mathrm{Na}$ tradução, houve uma generalização, não especificando o nome dos exames. Ressaltamos que os outros dois exames mencionados em inglês (CBC e Chem 7) também são "exames de sangue".

Abaixo, apresenta-se um gráfico com a porcentagem dos procedimentos apresentada nesta pequena análise de um episódio do seriado ER: 
Collet, T.; Emmel, I. - Terminologia em seriados médicos: os procedimentos de tradução na legendagem

Gráfico 2 - Procedimentos no seriado ER

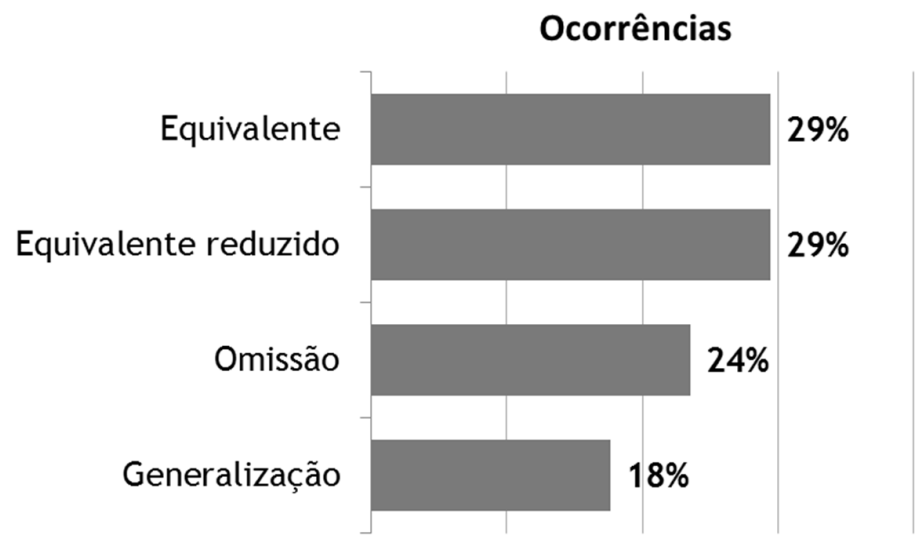

Fonte: Elaborado pelas autoras.

A tradução por equivalentes ou equivalentes reduzidos representou a maior porcentagem nos procedimentos (58\%), ou seja, 10 das 17 ocorrências dos termos nesse episódio. Ainda que o número de omissões tenha sido representativamente alto (4 de 17), dois termos foram omitidos em uma mesma fala que não foi traduzida para legendas.

\section{Uma breve comparação dos seriados}

No primeiro episódio analisado de House $\left(1^{\circ}\right.$ episódio da segunda temporada), foram encontrados 7 termos (arterial blood gas test, blood test, $\mathrm{CT}, \mathrm{MRI}$, respirator, urine test e x-ray) e no segundo, outros 11 diferentes (angio, angiogram, autopsy, blood work, cardiac bypass machine, cooling apparatus, echo, plethysmorgraphy, sat monitor, tox screen e VQ). No episódio analisado de ER foram encontrados 10 termos (blood gas, blood work, CBC, Chem-7, chest film, chest x-ray, CT, monitor, nebulizer e type and cross)). Apesar de o número de termos ser menor no primeiro episódio do seriado House 
Collet, T.; Emmel, I. - Terminologia em seriados médicos: os procedimentos de tradução na legendagem

(7 termos) que no seriado ER (10 termos), o número de ocorrências é maior naquele (houve 20 ocorrências no primeiro episódio de House e 33 no segundo, para 19 no ER). Isso se justifica, aparentemente, na razão de o seriado House ter o foco no tratamento de um único paciente, assim, para fazer o diagnóstico, os termos vão se repetindo (é mandado fazer o exame, depois volta o resultado e discute-se o mesmo). Deve-se observar que o foco do seriado House está em diagnosticar uma doença, que geralmente é rara, por isso, a realização de tantos exames; já no seriado ER ocorrem várias cirurgias, talvez uma análise da terminologia médica relacionada à instrumentação ou nome das cirurgias trouxesse um número mais representativo de termos, mas esta é apenas uma hipótese.

\section{Considerações finais}

Em relação à tradução da terminologia, apesar de ter-se analisado somente um episódio do seriado ER, o predomínio da tradução por equivalentes e equivalentes reduzidos, assim como no seriado House, analisado em Collet (2012), mostra como os termos são importantes dentro da comunicação especializada e, por isso, se mantêm nas legendas, cumprindo a função dos termos, que, segundo Cabré (1999), é a de representar e transmitir o conhecimento especializado. Isso indica que também na tradução se revela uma preocupação de conservação dessa parte determinante do discurso especializado. E demonstra ainda, em certo sentido, uma preocupação do tradutor em manter os termos. Além disso, os termos em si parecem conferir mais veracidade ao texto, dando a impressão de ser mais “médico" e menos lúdico/ficcional/de mera distração televisiva.

Este trabalho mostrou a prevalência da tradução por equivalentes em dois seriados de ficção, porém, observa-se que uma análise com mais episódios 
Collet, T.; Emmel, I. - Terminologia em seriados médicos: os procedimentos de tradução na legendagem

e termos deveria ser feita para confirmar se esta é uma constante neste tipo de programa televisivo.

\section{Referências bibliográficas}

AMERICAN CANCER SOCIETY. Disponível em: www.cancer.org/cancer/news/features/the-abcs-of-cancer-testing-decodingcommon-abbreviations. Acesso em: 02 maio 2013.

AMERICAN ASSOCIATION FOR CLINICAL CHEMISTRY. Dinsponível em: www.aacc.org/Pages/default.aspx. 12 maio 2013.

ASADIC. Alfabeto da saúde. Dicionários Online. Asadic Editora. Disponível em: www.online.asadic.com/verbetes/_indice_geral.htm. 31 out. 2011.

BaJAJ. B. C. Equivalence. In: MundaY, J. (Ed.) The Routledge Companion to Translation Studies. New York: Routledge, 2009: 185-186.

BARRos, L. A. Curso básico de Terminologia. São Paulo: Edusp, 2004: 285.

CABRÉ, M. T. La terminología. Representación y comunicación. Barcelona: Universitat Pompeu Fabra, 1999: 369.

CARVAlHo, C. A. A tradução para legendas: dos polissistemas à singularidade do tradutor. Dissertação de mestrado. Pontifícia Universidade Católica do Rio de Janeiro, 2005: 160.

DEAN, L. Blood groups and red cell antigens. Bethesda (MD): National Center for Biotechnology Information (US), 2005. Disponível em: www.ncbi.nlm.nih.gov/books/NBK2265/. Acesso em: 03 nov. 2011.

EMmeL, I. 0 'fazer' terminológico X o 'fazer' tradutório. Uma aplicação prática na área de especialidade: tradutologia. Dissertação de mestrado. UFSC, 1998. pp. 154.

ER. Plantão médico. Primeira Temporada. DVD. Warner Bross, 2004.

FinatTo, M. J. B. A definição dos termos técnico-científicos no âmbito dos estudos de terminologia. Revista Estudos da Linguagem, Belo Horizonte, v.11, n.1, jan./jun. 2003, pp. 197-222.

Holtz, A. A ciência médica de House. Tradução de Adriana Rieche. $7^{\text {a }}$ edição. Rio de Janeiro: Best Seller, 2008: 285.

Houalss, A. (Ed.) Dicionário eletrônico Houaiss da língua portuguesa. Versão 2.0a. Objetiva, 2007. CD-ROM. 
Collet, T.; Emmel, I. - Terminologia em seriados médicos: os procedimentos de tradução na legendagem

HousE, M.D. Segunda Temporada. Universal Pictures do Brasil, 2007. DVD (960 min.). Legendado Português e inglês.

HURTADO ALBIR, A. Traducción y traductología. Introducción a la traductología. $5^{\mathrm{a}}$ edición. Madrid: Cátedra, 2011: 695.

KRIEger, M. da G.; MaCiel, A. M. B.; FinatTo, M. J. B. Terminologia das Leis do Meio Ambiente: Princípios Teórico-Metodológicos. TradTerm, 6, 2000, pp. 143169. Disponível em: www.revistas.usp.br/tradterm/article/view/49520. Acesso em: 13 ago. 2013.

KRIEGER, M. da G.; FinATTO, M. J. B. Introdução à terminologia: teoria e prática. SP: Contexto, 2004: 223.

LAB Tests online. Produced by the AMERICAN Association for Clinical Chemistry. Disponível em: www.labtestsonline.org/understanding/analytes/cbc/tab/test. Acesso em: 12 maio 2013.

LEITE, M. D. (Org.). Dicionário Digital de Termos Médicos. Português. Disponível em: www.pdamed.com.br/diciomed/pdamed_0001_aa.php. Acesso em: 15 out. 2009.

MARTINEZ, S. L. Tradução para legendas: uma proposta para a formação de profissionais. Dissertação de Mestrado. Pontifícia Universidade Católica do Rio de Janeiro, Rio de Janeiro, 2007. pp.97.

. Entrevista com Sabrina Martinez. Concedida à Thaís Collet e Rafael Matielo. In-Traduções. Revista do Programa de Pós-Graduação em Estudos da Tradução da UFSC. Edição 4, 2011. Não paginado. Disponível em: www. incubadora.periodicos.ufsc.br/index.php/intraducoes/article/view/1792 /2013. Acesso em: 10 jul. 2013.

MEDICINENET. Com. Disponível em: http://www.medicinenet.com. Acesso em: 10 out. 2011.

MEDLINE PLUS. US national library of Medicine. Disponível em: www.nlm.nih.gov/medlineplus/. Acesso em: 15 out. 2011.

MEDTERMS. Medical dictionary. Disponível em: www.medterms.com/script/main/hp.asp. Acesso em: 15 out. 2011.

Molina, L; HURTADo AlBiR, A. Translation Techniques Revisited: A Dynamic and Functionalist Approach. Meta: Translators' J ournal, vol. 47, n 4, 2002, pp. 498512.

NADALE, M. As mentes de House. Super interessante, ed. 271, nov 2009. Disponível em: www.super.abril.com.br/cultura/mentes-house-625152.shtml. Acesso em: 29 jun. 2011. 
Collet, T.; Emmel, I. - Terminologia em seriados médicos: os procedimentos de tradução na legendagem

SHORE, D. Behind the Scenes at 'House'. Entrevista publicada em: 29 jan. 2006. Disponível em: www.etonline.com/tv/2006/01/35979/index.html. Acesso em: 14 out. 2009.

SHUTTLEWORTH, M.; COWIE, M. Dictionary of Translation Studies. Manchester: St. Jerome, 1997: 233.

TeRmiUm PLUS. The Government of Canada's terminology and linguistic data bank. Disponível em: www.btb.termiumplus.gc.ca. Acesso em: 10 out. 2011.

THOMAS, C. (coord.). Dicionário médico enciclopédico Taber. Tradução Dr. Fernando Gomes do Nascimento. 17 ed. (1 ed. brasileira). Barueri: Manole, 2000. 